\title{
Article \\ Cardiovascular Evaluation of Liver Transplant Patients by Using Coronary Calcium Scoring in ECG-Synchronized Computed Tomographic Scans
}

\author{
Anna Bettina Roehl ${ }^{1, *}$, Marc Hein ${ }^{1}{ }^{(}$, Johanna Kroencke ${ }^{1}$, Felix Kork ${ }^{1}$, Alexander Koch ${ }^{2}{ }^{(0)}$, Anne Andert ${ }^{3}$, \\ Michael Becker ${ }^{4}$, Jonas Schmöe ${ }^{5}$ and Sebastian Daniel Reinartz ${ }^{5}$ \\ 1 Department of Anesthesiology, Medical Faculty, RWTH Aachen University, 52074 Aachen, Germany; \\ mhein@ukaachen.de (M.H.); jkroencke@ukaachen.de (J.K.); fkork@ukaachen.de (F.K.) \\ 2 Department of Internal Medicine III, Gastroenterology, Metabolic Diseases and Intensive Care, \\ Medical Faculty, RWTH Aachen University, 52074 Aachen, Germany; akoch@ukaachen.de \\ 3 Department of General, Visceral and Transplantation Surgery, Medical Faculty, RWTH Aachen University, \\ 52074 Aachen, Germany; aandert@ukaachen.de \\ 4 Department of Cardiology, Nephrology and Intensive Care, Rhein-Maas Hospital, 52146 Würselen, Germany; \\ michael.becker@rheinmaasklinikum.de \\ 5 Department of Radiology, Medical Faculty, RWTH Aachen University, 52074 Aachen, Germany; \\ jonae.schmoe@posteo.de (J.S.); sreinartz@ukaachen.de (S.D.R.) \\ * Correspondence: aroehl@ukaachen.de; Tel.: +49-24180-80179
}

\section{check for}

updates

Citation: Roehl, A.B.; Hein, M.; Kroencke, J.; Kork, F.; Koch, A.; Andert, A.; Becker, M.; Schmöe, J.; Reinartz, S.D. Cardiovascular Evaluation of Liver Transplant Patients by Using Coronary Calcium Scoring in ECG-Synchronized Computed Tomographic Scans. J. Clin. Med. 2021, 10, 5148. https:// doi.org/10.3390/jcm10215148

Academic Editor: Matthias Biebl

Received: 21 September 2021 Accepted: 1 November 2021 Published: 2 November 2021

Publisher's Note: MDPI stays neutral with regard to jurisdictional claims in published maps and institutional affiliations.

Copyright: (c) 2021 by the authors. Licensee MDPI, Basel, Switzerland. This article is an open access article distributed under the terms and conditions of the Creative Commons Attribution (CC BY) license (https:/ / creativecommons.org/licenses/by/ $4.0 /)$.

\begin{abstract}
Background: The goal of cardiac evaluation of patients awaiting orthotopic liver transplantation (OLT) is to identify the patients at risk for cardiovascular events (CVEs) in the peri- and postoperative periods by opportunistic evaluation of coronary artery calcium (CAC) in non-gated abdominal computed tomographs (CT). Methods: We hypothesized that in patients with OLT, a combination of Lee's revised cardiac index (RCRI) and CAC scoring would improve diagnostic accuracy and prognostic impact compared to non-invasive cardiac testing. Therefore, we retrospectively evaluated 169 patients and compared prediction of CVEs by both methods. Results: Standard workup identified 22 patients with a high risk for CVEs during the transplant period, leading to coronary interventions. Eighteen patients had a CVE after transplant and a CAC score $>0$. The combination of CAC and RCRI $\geq 2$ had better negative (NPV) and positive predictive values (PPV) for CVEs (NPV 95.7\%, PPV 81.6\%) than standard non-invasive stress tests (NPV 92.0\%, PPV 54.5\%). Conclusion: The cutoff value of $C A C>0$ by non-gated CTs combined with RCRI $\geq 2$ is highly sensitive for identifying patients at risk for CVEs in the OLT population.
\end{abstract}

Keywords: orthotopic liver transplantation; cardiac assessment; coronary calcium score; coronary artery disease; stress testing

\section{Introduction}

Cardiovascular disease is the leading cause of non-graft-related death after orthotopic liver transplantation (OLT, LT) [1]. As patients listed for LT become older and sicker, and end-stage liver disease (ESLD) even enhances coronary artery disease (CAD), a sorrow cardiac assessment has to be performed in all patients [2,3]. Identification of an OLT patient with a coronary artery disease (CAD) is of importance for organ matching as well as for post-transplant surveillance $[4,5]$. The prevalence of CAD in patients considered for OLT ranges from $7.1 \%$ to $36.8 \%$ [6-8], mainly due to pre-existing co-morbidities. In patients with non-alcoholic steatosis hepatis (NASH), CAD prevalence rises up to $52.8 \%$ [9] due to increased inflammation. Post-transplant, the non-graft-related risk of cardiac death is about $10 \%[10,11]$. Due to donor shortage, the use of extended criteria donor (ECD) organs had already increased up to 50\% in 2012 [12-14]. ECD organs are associated with a significant postreperfusion syndrome [4], which leads to relevant hemodynamic compromise during 
the transplantation and possible functional impairment in the transplanted liver. Therefore, cardiac evaluation of the transplant recipient becomes even more important. The liver transplant recipient is especially prone to cardiovascular complications due to development or aggravation of any pre-existing metabolic syndrome such as arterial hypertension, dyslipidemia, obesity, renal injury, etc. Post-transplant indispensable immunosuppressive therapy even enhances any pre-existing metabolic syndrome and thus CAD [15,16].

There is no consensus on the preferred screening test to detect CAD in the pre-LT population nor for post-LT cardiac evaluation. The methods of cardiac assessment differ from site to site $[3,8,17]$. The American Heart Association and the American College of Cardiology Foundation suggest non-invasive stress testing following cardiovascular risk assessment for patients without active cardiac disease [18]. The American Study of Liver Diseases and the American Society of Transplantation advocate for invasive cardiac testing for all adult patients before OLT [19]. Cardiac catheterization has an increased risk in end-stage liver disease (ESLD) patients due to their altered coagulability [20,21].

Non-invasive testing for CAD may be performed by dobutamine stress echocardiography (DES) [22], cardiac single-photon emission computed tomography (SPECT) [23] or ECG-synchronized coronary computed tomography angiography (CCTA) [24,25]. Many patients with ESLD are incapable of performing activity to diagnose any cardiac symptoms due to the impairment of their aerobic capacity [26]. Detection of coronary artery calcification (CAC) by ECG-synchronized CT was initially introduced by Agatston [27]. Different groups verified that with the Agatston score $=0$, an exclusion of CAC can be reliably detected in non-synchronized chest CT with an NPV of 91.6\% [22,28]. Even nonECG-synchronized CT scans of the abdomen in septic patients reveal the high negative predictive value of cardiovascular events by calcium scoring [29]. Each patient receives numerous $\mathrm{CT}$ scans of the upper abdomen during liver transplant evaluation wherein the heart is largely depicted. In these scans, the information about whether there is CAC can be easily measured without any further radiation exposure. Thus, the aim of this study was to evaluate the opportunistic benefit of measuring CAC scores from standard CT scans prior to LT by correlating with observed CVE in the postoperative period to standard cardiac assessment.

\section{Materials and Methods}

\subsection{Patient Cohort}

This retrospective cohort study was approved by the local ethics committee (University Hospital RWTH Aachen, EK 291/13). Data were collected from the electronic health records and the liver transplant database at the University Hospital Aachen. Our analyses were conducted with adherence to the Strengthening the Reporting of Observational Studies in Epidemiology (STROBE) guidelines [30].

Two hundred and seventy patients receiving an OLT in our university hospital from October 2010 to January 2018 were screened for study enrollment. Patients met the inclusion criteria if a pre-transplant evaluation included non-ECG-synchronized CT, which included scans covering the heart to a large extent. The follow-up of all patients continued until January 2019 by checking the electronical data recordings of the hospital. Patients who chose not to follow up in our hospital were asked to provide their newest medical records from their treating physician.

Overall cardiovascular risk was assessed by Lee's revised cardiac index (RCRI) [31]. Pre-transplant, all patients received an echocardiography at rest. Patients who were not able to climb 2 stairs without dyspnea, with known coronary artery disease (CAD) or two of the following risk factors: diabetes mellitus, older than 50 years of age, smoking, hypotension or fat metabolism disorder, received either a dobutamine stress echo (DSE) [32], a singlephoton emission computed tomography (SPECT) [24,26], a magnetic resonance imaging (MRI) [32,33] of the heart or an exercise ECG (ergometry). In cases of symptomatic CAD, as well as of a positive non-invasive test, an invasive coronary angiography (ICA) [32] was performed. 


\subsection{Definition of Endpoints}

The primary endpoint of this study was the occurrence of cardiovascular events (CVE) following OLT. CVE is defined as acute coronary syndrome, necessity of coronary revascularization or cardiopulmonary resuscitation. Death was not included as cause of death was frequently unclear. Therefore, the aim of this study was to describe the predictive value of CAC scores obtained from non-ECG-synchronized CT for CVE and compare them to RCRI $\geq 2$ and pathologic non-invasive stress testing of the heart.

\subsection{Coronary Artery Calcium (CAC) Scoring}

The quantitative evaluation of coronary artery calcifications (CAC) was performed using non-ECG-synchronized CT scans. These were non-contrast or contrast-enhanced examinations of the abdomen or liver that were performed as part of the regular pre-OLT work-up $[34,35]$.

Normally, this protocol consists of a native, arterial, portal venous and a late phase of the venous contrast medium and routinely covers large parts of the heart. When the native examination has been omitted, the venous contrast agent phase or the phase with the biggest heart coverage is preferred for measuring CAC.

In case of absence of the native phase and due to vascular attenuation by the contrast medium, the threshold value for identifying calcium was chosen to be two standard deviations above the vascular mean value determined by ROI (Region of Interest) measurement. The standard reconstruction kernel (B30f) and a slice with $5 \mathrm{~mm}$ thickness were selected. Two experienced readers quantified, in consensus, the resulting Agatston and volume scores for all coronary vessels and aortic valve leaflets.

\subsection{Statistical Analysis}

The differences between groups for parametric data were analyzed by t-test or MannWhitney $U$ test and displayed by mean and standard deviation or range (minimummaximum). Nominal or ordinal scaled data were investigated for significant differences between groups by the chi-square test and reported as absolute and relative occurrence (SPSS 24.0, IBM statistics, IBM, Ehningen, Germany). The sensitivity, specificity, positive predictive value (PPV), negative predictive value (NPV) and accuracy of each test to predict CVE were calculated according to the usual definitions. Furthermore, only the combination of an RCRI $\geq 2$ and CAC $>0$ was of interest as they require no additional testing. The McNemar test was used to compare the sensitivities, specificities and diagnostic accuracy of the different scores or tests.

\section{Results}

One hundred and sixty-nine patients met the inclusion criteria of non-ECG-synchronized CT scans including large parts of the heart. During the follow-up period (1797 days (MW), range 1-3268) after OLT, 18/169 (10.7\%) patients showed a CVE. Patients with CVE were older and more often male, but they had an equal BMI, labMELD and distribution of underlying cause of liver disease. There were no significant differences in left ventricular function (LVEF) pre-transplant. Patients were more often already diagnosed with hypertension and diabetes before OLT. Their diagnosis of CAD was also reflected by their differences in medication by aspirin, $\mathrm{B}$-blockers and statins (see Table 1 ). Two or more risk factors were reported in patients $49 / 169(29 \%)$ of which $11(28.2 \%)$ showed a CVE post OLT. The PPV and the NPV for two or more RCRI to detect patients for CVE after OLT were $77.6 \%$ and $94.2 \%$. Additional data are given in Table 2 . 
Table 1. Demographic and clinical characteristics of 169 single-center liver transplant recipients. Patients were discriminated between patients without a cardiovascular event (w/o CVE) and with a cardiovascular event post-transplant (with CVE).

\begin{tabular}{|c|c|c|c|c|}
\hline & $\begin{array}{c}\text { All } \\
n=169\end{array}$ & $\begin{array}{c}\text { w/o CVE } \\
\text { Post-Transplant } \\
n=151\end{array}$ & $\begin{array}{c}\text { with CVE } \\
\text { Post-Transplant } \\
n=18\end{array}$ & $p$ \\
\hline Age (years) & $53.4 \pm 11.7$ & $52.8 \pm 12.1$ & $58.7 \pm 6.2$ & 0.043 \\
\hline Sex (female) & $58(34.3 \%)$ & $50(33.1 \%)$ & $4(22.2 \%)$ & $<0.001$ \\
\hline BMI $\left(\mathrm{kg} / \mathrm{cm}^{2}\right)$ & $26.7 \pm 5.6$ & $26.7 \pm 5.6$ & $27.5 \pm 5$ & 0.564 \\
\hline labMELD & $17.8 \pm 8.8$ & $18 \pm 9$ & $16.7 \pm 6.9$ & 0.562 \\
\hline Reason for transplantation & & & & 0.842 \\
\hline Alcoholic Cirrhosis & $50(26 \%)$ & $41(27.2 \%)$ & $9(50 \%)$ & \\
\hline $\mathrm{HCC}$ & $19(11.2 \%)$ & $17(11.3 \%)$ & $2(11.1 \%)$ & \\
\hline Acute Liver Failure & $16(9.5 \%)$ & $15(9.9 \%)$ & $1(5.5 \%)$ & \\
\hline ACLF & $5(3 \%)$ & $5(3.3 \%)$ & 0 & \\
\hline PSC & $13(7.7 \%)$ & $12(7.9 \%)$ & $1(5.5 \%)$ & \\
\hline $\mathrm{HBV} / \mathrm{HCV}$-Cirrhosis & $14(8.3 \%)$ & $12(7.9 \%)$ & $2(11.1 \%)$ & \\
\hline Graft Failure & $1(0.6 \%)$ & $1(0.6 \%)$ & 0 & \\
\hline NASH & $13(7.7 \%)$ & $12(7.9 \%)$ & $1(5.5 \%)$ & \\
\hline Other & $13(7.7 \%)$ & $13(8.6 \%)$ & $1(5.5 \%)$ & \\
\hline CAC volume & $76.4 \pm 272.2$ & $41.6 \pm 110$ & $367.8 \pm 724.6$ & $<0.001$ \\
\hline CAC mass & $15.0 \pm 52.6$ & $8.0 \pm 21.3$ & $73.5 \pm 138.9$ & $<0.001$ \\
\hline Agatston score & $82.6 \pm 317.1$ & $41.7 \pm 113.7$ & $425.0 \pm 860.7$ & $<0.001$ \\
\hline Agatston score $=0$ & $114(67.5 \%)$ & $110(72.8 \%)$ & $4(2.2 \%)$ & \\
\hline Diabetes & $54(32 \%)$ & $42(27.8 \%)$ & $12(66.7 \%)$ & 0.001 \\
\hline Hypertension & $58(34.3 \%)$ & $47(31.1 \%)$ & $11(61.1 \%)$ & 0.011 \\
\hline Renal insufficiency & $53(31.4)$ & $47(31.1 \%)$ & $6(59 \%)$ & 0.849 \\
\hline TIA/apoplex & $3(1.8 \%)$ & $2(1.3 \%)$ & $1(5.6 \%)$ & 0.199 \\
\hline Statins & $19(11.2 \%)$ & $13(8.6 \%)$ & $6(33.3 \%)$ & 0.002 \\
\hline B blocker & $18(10.7 \%)$ & $77(51 \%)$ & $11(61 \%)$ & 0.417 \\
\hline ASS & $14(8.3 \%)$ & $12(7.9 \%)$ & $2(11.1 \%)$ & 0.645 \\
\hline LV ejection fraction (\%) & $61.0 \pm 6.6$ & $60.8 \pm 6.7$ & $62.1 \pm 6.2$ & 0.622 \\
\hline Smoking & $30(17.8)$ & $24(16 \%)$ & $6(33.3 \%)$ & 0.188 \\
\hline known CAD & 18 & $11(7.2 \%)$ & $7(3.8 \%)$ & $<0.001$ \\
\hline Pathologic Stress Test & 13 & 8 & 5 & $<0.001$ \\
\hline rCRI $(n)$ & & & & 0.002 \\
\hline 1 & 120 & $113(94.2 \%)$ & $7(5.8 \%)$ & \\
\hline 2 & 38 & $31(81.6 \%)$ & $7(18.4 \%)$ & \\
\hline 3 & 11 & $7(63.6 \%)$ & $4(36.4 \%)$ & \\
\hline ICA $(n)$ & 22 & 16 & 6 & 0.007 \\
\hline With PCI $(n)$ & 3 & 1 & 2 & 0.001 \\
\hline
\end{tabular}

BMI: body mass index, rCRI: Lee's revised cardiac index, CAD: coronary artery disease, DSE: dobutamine stress echo, SPECT: single-photon emission tomography, ICA: invasive coronary angiography, PCI: percutaneous coronary intervention, LV ejection fraction: left ventricular ejection fraction, MRI: magnetic resonance imaging, Ergo: ergometry, HCC: hepatocellular carcinoma, ACLF: acute-on-chronic liver failure, PSC: primary sclerosing cholangitis, HBV: hepatitis B virus, HCV: hepatitis C virus, NASH: non-alcoholic steatosis hepatis, labMELD: laboratory model of end-stage liver disease, MACE: major adverse cardiac events, ICA: invasive coronary angiography. 
Table 2. Accuracy of the stress tests and Agatston score to detect obstructive coronary artery disease.

\begin{tabular}{ccccc}
\hline & Pathol. Stress-Test & RCRI $\geq \mathbf{2}$ & Agatston $>\mathbf{0}$ & RCRI $\geq \mathbf{2}$ and Agatston $>\mathbf{0}$ \\
\hline Sensitivity & 38.5 & 61.1 & 77.8 & 77.8 \\
\hline Specificity & 93.9 & 74.8 & 72.8 & 58.9 \\
\hline PPV & 54.5 & 77.6 & 74.5 & 81.6 \\
\hline NPV & 92.0 & 94.2 & 96.5 & 95.7 \\
\hline Accuracy & 87.4 & 73.4 & 73.4 & 60.9 \\
\hline$p$-Values & & & 0.041 \\
\hline vs. stress test & & $<0.001$ & $<0.001$ & $<0.001$ \\
\hline vs. RCRI & & 0.470 & $<0.001$ \\
\hline vs. Agatston $>0$ & & & \\
\hline
\end{tabular}

rCRI: Lee's revised cardiac index, PPV: positive predictive value, NPV: negative predictive value.

For 111 patients, the extended pre-transplant cardio-workup included non-invasive cardiac stress testing. Methods for non-invasive cardiac stress testing differed due to the availability of the testing method as well as the tolerance of the patient for the respective exercise testing facility and to the adverse effects of the different pharmacologic agents. DSE was the most frequent test, followed by SPECT and MRI. The fewest number of patients $(5 / 111)$ passed an ergometric stress test. SPECT demonstrated the highest rate of pathologic results $(p=0.003)$. Fifty-eight patients were transplanted without a stress test before OLT. The reasons for missing stress tests are not comprehensible in this retrospective analysis (e.g., patients on the ICU ward before OLT, timely matters before OLT). The distribution of patients having a stress test before OLT showing a CVE post-OLT $(29 / 111,26 \%)$ is comparable to the number of patients without a stress test having a CVE $(16 / 58,18 \%)$ (see Table 3).

Table 3. Number of patients with and without a non-invasive stress test and their respective amount of CVE.

\begin{tabular}{ccccc}
\hline & & & CVE & Total \\
\hline \multirow{3}{*}{ non-invasive } & normal & 77 & $23(23 \%)$ & 100 \\
stress test & pathol. & 5 & $6(55 \%)$ & 11 \\
& total & 82 & $29(26 \%)$ & 111 \\
& no test & 42 & $16(18 \%)$ & 58 \\
& & 124 & $45(27 \%)$ & 169 \\
\hline
\end{tabular}

Due to our pre-transplant cardio-workup, 13/111 patients were identified with a suspected obstructive CAD following non-invasive stress testing. Nine patients were scheduled for invasive testing without a prior non-invasive stress test, due to being highly suspicious for obstructive coronary artery disease (medical history) as well as due to contraindications for non-invasive stress testing. Twenty-two patients received an invasive coronary angiography (ICA). In summary, invasive testing was more frequent in patients with CVE after transplant. In $3 / 22$ patients receiving an ICA, a percutaneous coronary intervention was performed without repeating the stress test prior to OLT. In the follow-up period, only one of these patients suffered from a non-fatal NSTEMI, but two died due to progressing LV-insufficiency combined with ARDS and cerebral abscesses, respectively.

We discriminated between patients without an Agatston score at all (CAC $=0, n=114$, $67.5 \%)$ and those patients with an Agatston score $>0$ (CAC $>0, n=55 ; 32.5 \%)$. More patients without CVE had CAC $=0(p<0.001)$, while $15 / 18$ with CVE post-OLT demonstrated a positive non-invasive stress test or $C A C>0$ (vs. $45 / 151 ; p<0.001$ ). The highest sensitivity to predict CVE post-transplant was given for a CAC $>0(77.8 \%)$. A positive stress test showed the highest specificity to identify patients at risk for CVE post-OLT. Although, 
the PPV for a pathologic stress test was only $54.5 \%$ in our setting. On the contrary, the combination of two or more RCRI and CAC > 0 showed a PPV of $81.6 \%$ for CVE post-OLT. The negative predictive values for stress testing $(\mathrm{NPV}=92.0 \%)$ were comparable to a $\mathrm{CAC}=0$ and $\mathrm{RCRI} \geq 2(\mathrm{NPV}=96.5 \%)$.

\section{Discussion}

In this single-center retrospective analysis of 169 OLT recipients, we found a $10.7 \%$ incidence of CVE post-OLT. This occurrence is comparable to published data [36]. We demonstrated in our cohort that CVE post-OLT could be best predicted by the combination of $\mathrm{RCRI} \geq 2$ and $\mathrm{CAC}>0$.

There are two different etiologies for perioperative myocardial infarction: on demand myocardial ischemia and coronary plaque rupture [37]. Non-invasive stress testing methods, which are aiming for myocardial wall motion (DSE) disturbances and perfusion/glucose utilization (MRI, SPECT) as well as the RCRI, may depict patients susceptible to demand myocardial ischemia. Imaging modalities addressing coronary plaque visualization (CCTA) may detect culprit lesions that lead to acute coronary syndromes (napkin-ring sign, low attenuation plaque) [38]. Furthermore, CCTA provides a high negative predictive value for excluding significant CAD [39].

In OLT patients, the diagnostic accuracy for obstructive coronary artery disease by non-invasive stress testing, as well as of invasive cardiac diagnostic by ICA, is discussed. In a comprehensive systematic review, Konerman et al. reported the striking variability regarding sensitivity for cardiovascular events by different cardiac imaging modalities pre-OLT [36]. DSE might result in false negative results due to altered hemodynamics in ESLD. For example, high-output failure, cirrhotic cardiomyopathy and use of beta-blockers, as well as anemia, may disguise coronary artery disease in ESLD patients [2,40]. This may result in a preterm interruption of DSE due to global cardiac insufficiency. DSE has been shown to have a low sensitivity (32\%) and PPV (37\%) in predicting CAD [41] in the OLT population [40]. SPECT imaging is even an inaccurate screening test in ESLD patients with low sensitivity of $35 \%$ due to endothelial dysfunction in liver cirrhosis [41]. Cardiac MRI has gained increasing attention in pre-OLT screening as the morphology of the left and right ventricle can be equally assessed by an independent observer [42,43]. Reddy et al. described a sensitivity of $50 \%$ to detect CAD by MRI and a specifity of $98 \%$ [42]. Wray et al. showed the high diagnostic accuracy for CAD by ICA in OLT patients [6]. Although we only had the small number of two patients receiving a PCI pre-transplant, PCI could not prevent CVE after transplant in these patients. Two out of three patients showed a CVE after the transplantation. Wray et al. described a trend of a higher mortality in patients with significant CAD and PCI [6] as periprocedural risk increases due to the altered state of coagulability in ESLD. ICA is highly sensitive for diagnosing stenotic CAD. Hence, the consistency of the coronary plaque structure, and therefore the vulnerability of this plaque, is of further interest. Imaging modalities such as DSE, SPECT and MRI are able to identify the patient with symptomatic CAD due to demand myocardial ischemia [39,44]. One of the advantages of CCTA, besides being the benchmark for chronic coronary syndrome patients [39], is the non-invasive detection of coronary artery stenosis and the vulnerability of the underlying plaque [45]. Still, these data have to be verified in this special cohort of OLT patients.

The 2019 guidelines of the European Society of Cardiologists implemented CAC scoring to determine the clinical likelihood of obstructive CAD in pre-operative work-up for major non-cardiac surgery [39]. CAD is predictable by screening for CAC even in non-gated chest CTs [6]. Our study demonstrated the high negative predictive value of CAC (96.5\%) discovered on non-ECG-synchronized CTs in these patients. Our data outgo the reported negative predictive value (91.6\%) of Agatston $=0$ for CAD in non-gated thorax CT by Azour et al. [22]. 
Joshi et al. as well as Blaha et al. described comparable findings that a CAC $=0$ has a high 10-year diagnostic screening role $[46,47]$. As for the patients at risk of coronary plaque rupture, additional coronary artery CT angiography may help to identify these lesions [48].

Our results suggest that CAC scoring and evaluation of RCRI may reduce the number of non-invasive stress tests and ICAs. Following our results published by Mechelink et al., echocardiography at rest with strain analysis in combination with CAC scoring as well as RCRI will even help to improve the identification of patients at risk [49].

All of the 169 OLT patients reported in this study were treated in the same center under standardized procedures pre-transplant, intraoperatively and post-transplant $[4,50]$. Therefore, we achieved a homogeneous single-center study sample, though a single-center study limits the external validity of the results. In Germany in 2019, 22 transplant centers reported not less than 1571 liver grafts, with each transplant center following their own standard operating protocol. Furthermore, the partial retrospective design of our analyses could impair data quality. Systematic errors as well as any observer bias may not be excluded.

\section{Conclusions}

Determining the RCRI of a patient and CAC $=0$ on routine non-gated CT will help to better identify patients with CAD at risk for a CVE after OLT. The high negative predictive value of Agatston $=0$ combined with RCRI $\geq 2$ will narrow down the number of patients who have to receive a full cardiac workup before OLT. This concept is particularly practical for the evaluation of highly compromised patients, for example in the intensive ward pre-transplant. Identifying patients at risk for CVE during and after OLT will enable a better organ-to-recipient match regarding the increasing number of ECD organs as well as thorough post-transplant monitoring of these patients.

Author Contributions: Conceptualization, A.B.R., S.D.R., M.H. and M.B.; methodology, S.D.R., J.K. and M.H.; formal analysis, J.K., M.H., J.S. and S.D.R.; investigation, A.B.R., M.H., J.K., F.K., M.B., J.S., A.A., A.K. and S.D.R.; data curation, F.K., A.B.R., S.D.R. and M.H.; writing-original draft preparation, A.B.R. and S.D.R.; writing—review and editing, M.H., A.A., A.K., F.K., J.K., and J.S. All authors have read and agreed to the published version of the manuscript.

Funding: This research received no external funding.

Institutional Review Board Statement: The local ethics committee (University Hospital Aachen, EK 291/13) approved the analysis and waived the requirement of informed consent. The study was conducted according to the guidelines of the Declaration of Helsinki.

Informed Consent Statement: The local ethics committee waived the requirement of informed consent.

Data Availability Statement: The datasets generated and/or analyzed during the current study are not publicly available due to German Data Protection laws but are available from the corresponding author on reasonable request after approval of the local ethics committee and data safety board.

Acknowledgments: The analysis was conducted in the course of a doctoral thesis of J.K. at the Medical Faculty of the RWTH Aachen, Germany.

Conflicts of Interest: The authors declare no conflict of interest.

\section{References}

1. Albeldawi, M.; Aggarwal, A.; Madhwal, S.; Cywinski, J.; Lopez, R.; Eghtesad, B.; Zein, N.N. Cumulative risk of cardiovascular events after orthotopic liver transplantation. Liver Transplant. 2012, 18, 370-375. [CrossRef]

2. Soldera, J.; Camazzola, F.; Rodriguez, S.; Brandao, A. Cardiac stress testing and coronary artery disease in liver transplanta-tion candidates: Meta-analysis. World J. Hepatol. 2018, 10, 877-886. [CrossRef]

3. McCaughan, G.W.; Crawford, M.; Sandroussi, C.; Koorey, D.J.; Bowen, D.G.; Shackel, N.A.; Strasser, S.I. As-sessment of adult patients with chronic liver failure for liver transplantation in 2015: Who and when? Intern. Med. J. 2016, 46, 404-412. [CrossRef] 
4. Kork, F.; Rimek, A.; Andert, A.; Becker, N.J.; Heidenhain, C.; Neumann, U.P.; Kroy, D.; Roehl, A.B.; Rossaint, R.; Hein, M. Visual quality assessment of the liver graft by the transplanting surgeon predicts postreperfusion syndrome after liver transplantation: A retrospective cohort study. BMC Anesthesiol. 2018, 18, 29. [CrossRef]

5. Gallegos-Orozco, J.F.; Charlton, M.R. Predictors of Cardiovascular Events After Liver Transplantation. Clin. Liver Dis. 2017, 21, 367-379. [CrossRef]

6. Wray, C.; Scovotti, J.C.; Tobis, J.; Niemann, C.U.; Planinsic, R.; Walia, A.; Findlay, J.; Wagener, G.; Cywinski, J.B.; Markovic, D.; et al. Liver transplantation outcome in patients with angiographically proven coronary artery dis-ease: A multi-institutional study. Am. J. Transplant. 2013, 13, 184-191. [CrossRef]

7. Alexander, S.; Teshome, M.; Patel, H.; Chan, E.Y.; Doukky, R. The diagnostic and prognostic utility of risk factors defined by the AHA/ACCF on the evaluation of cardiac disease in liver transplantation candidates. BMC Cardiovasc. Disord. 2019, 19, 1-6. [CrossRef] [PubMed]

8. Ye, C.; Saincher, M.; Tandon, P.; Meeberg, G.; Williams, R.; Burak, K.W.; Bain, V.G. Cardiac work-up protocol for liver transplant candidates: Experience from a single liver transplant centre. Can J Gastroenterol. 2012, 26, 806-810. [CrossRef] [PubMed]

9. Patel, S.S.; Nabi, E.; Guzman, L.; Abbate, A.; Bhati, C.; Stravitz, R.T.; Reichman, T.; Matherly, S.C.; Driscoll, C.; Lee, H.; et al. Coronary artery disease in decompensated patients undergoing liver transplantation evaluation. Liver Transpl. 2018, 24, 333-342. [CrossRef]

10. Watt, K.D.; A Pedersen, R.; Kremers, W.K.; Heimbach, J.K.; Charlton, M.R. Evolution of Causes and Risk Factors for Mortality Post-Liver Transplant: Results of the NIDDK Long-Term Follow-Up Study. Arab. Archaeol. Epigr. 2010, 10, 1420-1427. [CrossRef]

11. Pruthi, J.; Medkiff, K.A.; Esrason, K.T.; Donovan, J.A.; Yoshida, E.M.; Erb, S.R.; Steinbrecher, U.P.; Fong, T. Analysis of causes of death in liver transplant recipients who survived more than 3 years. Liver Transplant. 2001, 7, 811-815. [CrossRef] [PubMed]

12. Manns, M.P. Liver Cirrhosis, Transplantation and Organ Shortage. Dtsch. Aerzteblatt Online 2013, 110, 83-84. [CrossRef]

13. Vodkin, I.; Kuo, A. Extended Criteria Donors in Liver Transplantation. Clin. Liver Dis. 2017, 21, 289-301. [CrossRef]

14. Braat, A.E.; Blok, J.J.; Putter, H.; Adam, R.; Burroughs, A.K.; Rahmel, A.O.; Porte, R.J.; Rogiers, X.; European Liver; Intestine Transplant Association (ELITA) and Eurotransplant Liver Intestine Advisory Committee (ELIAC); et al. The Eurotransplant donor risk index in liver trans-plantation: ET-DRI. Am. J. Transplant. 2012, 12, 2789-2796. [CrossRef]

15. Bardou, F.-N.; Guillaud, O.; Erard-Poinsot, D.; Chambon-Augoyard, C.; Thimonier, E.; Vallin, M.; Boillot, O.; Dumortier, J. Tacrolimus exposure after liver transplantation for alcohol-related liver disease: Impact on complications. Transpl. Immunol. 2019, 56, 101227. [CrossRef]

16. Becchetti, C.; Dirchwolf, M.; Banz, V.; Dufour, J.-F. Medical management of metabolic and cardiovascular complications after liver transplantation. World J. Gastroenterol. 2020, 26, 2138-2154. [CrossRef] [PubMed]

17. Główczyńska, R.; Galas, M.; Witkowska, A.; Ołdakowska-Jedynak, U.; Raszeja-Wyszomirska, J.; Krasuski, K.; Milkiewicz, P.; Krawczyk, M.; Zieniewicz, K.; Opolski, G. The Pre-Transplant Profile of Cardiovascular Risk Factors and Its Impact on Long-Term Mortality After Liver Transplantation. Ann. Transplant. 2018, 23, 591-597. [CrossRef]

18. Lentine, K.L.; Costa, S.P.; Weir, M.R.; Robb, J.F.; Fleisher, L.A.; Kasiske, B.L.; Carithers, R.L.; Ragosta, M.; Bolton, K.; Auerbach, A.D.; et al. Cardiac disease evaluation and management among kidney and liver transplantation candidates: A scientific statement from the American Heart Association and the American College of Cardiology Foundation. J. Am. Coll. Cardiol. 2012, 60, 434-480. [CrossRef] [PubMed]

19. Martin, P.; DiMartini, A.; Feng, S.; Brown, R., Jr.; Fallon, M. Evaluation for liver transplantation in adults: 2013 practice guideline by the American Association for the Study of Liver Diseases and the American Society of Transplantation. Hepatology 2013, 59, 1144-1165. [CrossRef] [PubMed]

20. Pillarisetti, J.; Patel, P.; Duthuluru, S.; Roberts, J.; Chen, W.; Genton, R.; Wiley, M.; Candipan, R.; Tadros, P.; Gupta, K. Cardiac catheterization in patients with end-stage liver disease: Safety and outcomes. Catheter. Cardiovasc. Interv. 2011, 77, 45-48. [CrossRef] [PubMed]

21. Lu, D.Y.; Saybolt, M.D.; Kiss, D.H.; Matthai, W.H.; Forde, K.A.; Giri, J.; Wilensky, R.L. One-Year Outcomes of Percutaneous Coronary Intervention in Patients with End-Stage Liver Disease. Clin. Med. Insights Cardiol. 2020, 14, 1179546820901491. [CrossRef]

22. Azour, L.; Kadoch, M.A.; Ward, T.J.; Eber, C.D.; Jacobi, A.H. Estimation of cardiovascular risk on routine chest CT: Ordinal coronary artery calcium scoring as an accurate predictor of Agatston score ranges. J. Cardiovasc. Comput. Tomogr. 2017, 11, 8-15. [CrossRef]

23. Baibhav, B.; Mahabir, C.A.; Xie, F.; Shostrom, V.K.; McCashland, T.M.; Porter, T.R. Predictive Value of Dobutamine Stress Perfusion Echocardiography in Contemporary End-Stage Liver Disease. J. Am. Hear. Assoc. 2017, 6. [CrossRef] [PubMed]

24. Kemmer, N.; Case, J.; Chandna, S.; Neff, G.W. The role of coronary calcium score in the risk assessment of liver transplant can-didates. Transplant. Proc. 2014, 46, 230-233. [CrossRef] [PubMed]

25. Kong, Y.-G.; Ha, T.-Y.; Kang, J.-W.; Hwang, S.; Lee, S.-G.; Kim, Y.-K. Incidence and Predictors of Increased Coronary Calcium Scores in Liver Transplant Recipients. Transplant. Proc. 2015, 47, 1933-1938. [CrossRef]

26. Sandal, S.; Chen, T.; Cantarovich, M. The Challenges With the Cardiac Evaluation of Liver and Kidney Transplant Candidates. Transplantation 2020, 104, 251-258. [CrossRef] [PubMed]

27. Agatston, A.S.; Janowitz, F.W.R.; Hildner, F.J.; Zusmer, N.R.; Viamonte, M., Jr.; Detrano, R. Quantification of coronary artery calcium using ultrafast computed tomography. J. Am. Coll. Cardiol. 1990, 15, 827-832. [CrossRef] 
28. Takx, R.A.; De Jong, P.; Leiner, T.; Oudkerk, M.; De Koning, H.; Mol, C.; Viergever, M.; Isgum, I. Automated Coronary Artery Calcification Scoring in Non-Gated Chest CT: Agreement and Reliability. PLoS ONE 2014, 9, e91239. [CrossRef]

29. Gupta, V.A.; Sousa, M.; Kraitman, N.; Annabathula, R.; Vsevolozhskaya, O.; Leung, S.W.; Sorrell, V.L. Coronary artery calcification predicts cardiovascular complications after sepsis. J. Crit. Care 2018, 44, 261-266. [CrossRef]

30. Von Elm, E.; Altman, D.G.; Egger, M.; Pocock, S.J.; Gøtzsche, P.C.; Vandenbroucke, J.P. The Strengthening the Reporting of Ob-servational Studies in Epidemiology (STROBE) statement: Guidelines for reporting observational studies. Lancet 2007, 370, 1453-1457. [CrossRef]

31. Lee, T.H.; Marcantonio, E.R.; Mangione, C.M.; Thomas, E.J.; Polanczyk, C.A.; Cook, E.F.; Sugarbaker, D.J.; Donaldson, M.C.; Poss, R.; Ho, K.K.L.; et al. Derivation and Prospective Validation of a Simple Index for Prediction of Cardiac Risk of Major Noncardiac Surgery. Circulation 1999, 100, 1043-1049. [CrossRef]

32. Becker, M.; Hundemer, A.; Zwicker, C.; Altiok, E.; Krohn, T.; Mottaghy, F.M.; Lente, C.; Kelm, M.; Marx, N.; Hoffmann, R. Detection of coronary artery disease in post-menopausal women: The significance of integrated stress imaging tests in a 4-year prognostic study. Clin. Res. Cardiol. 2015, 104, 258-271. [CrossRef]

33. Thiele, H.; Paetsch, I.; Schnackenburg, B.; Bornstedt, A.; Grebe, O.; Wellnhofer, E.; Schuler, G.; Fleck, E.; Nagel, E. Improved accuracy of quantitative assessment of left ventricular volume and ejection fraction by geometric models with steady-state free precession. J. Cardiovasc. Magn. Reson. 2002, 4, 327-339. [CrossRef]

34. Van der Bijl, N.; Joemai, R.M.; Geleijns, J.; Bax, J.J.; Schuijf, J.D.; de Roos, A.; Kroft, L.J. Assessment of Agatston coronary artery calcium score using contrast-enhanced CT coronary angiography. Am. J. Roentgenol. 2010, 195, 1299-1305. [CrossRef]

35. Bamberg, F.; Sommer, W.H.; Hoffmann, V.; Achenbach, S.; Nikolaou, K.; Conen, D.; Reiser, M.F.; Hoffmann, U.; Becker, C.R. Metaanalysis and systematic review of the long-term predictive value of assessment of coronary atherosclerosis by contrast-enhanced coronary computed tomog-raphy angiography. J. Am. Coll. Cardiol. 2011, 57, 2426-2436. [CrossRef]

36. Konerman, M.A.; Fritze, D.; Weinberg, R.L.; Sonnenday, C.J.; Sharma, P. Incidence of and Risk Assessment for Adverse Cardiovascular Outcomes After Liver Transplantation: A Systematic Review. Transplantation 2017, 101, 1645-1657. [CrossRef]

37. Thygesen, K.; Alpert, J.S.; Jaffe, A.S.; Chaitman, B.R.; Bax, J.J.; Morrow, D.A.; White, H.D.; Executive Group on behalf of the Joint European Society of Cardiology (ESC)/American College of Cardiology (ACC)/American Heart Association (AHA)/World Heart Federation (WHF) Task Force for the Universal Definition of Myocardial Infarction. Fourth Universal Definition of Myocardial Infarction (2018). Circulation 2018, 138, e618-e651. [CrossRef]

38. Yamamoto, H.; Kihara, Y.; Kitagawa, T.; Ohashi, N.; Kunita, E.; Iwanaga, Y.; Kobuke, K.; Miyazaki, S.; Kawasaki, T.; Fujimoto, S.; et al. Coronary plaque characteristics in computed tomography and 2-year outcomes: The PREDICT study. J. Cardiovasc. Comput. Tomogr. 2018, 12, 436-443. [CrossRef]

39. Knuuti, J.; Wijns, W.; Saraste, A.; Capodanno, D.; Barbato, E.; Funck-Brentano, C.; Prescott, E.; Storey, R.F.; Deaton, C.; Cuisset, T.; et al. 2019 ESC Guidelines for the diagnosis and management of chronic coronary syndromes. Eur. Heart J. 2020, 41, $407-477$. [CrossRef]

40. Nguyen, P.; Plotkin, J.; Fishbein, T.M.; Laurin, J.M.; Satoskar, R.; Shetty, K.; Taylor, A.J. Dobutamine stress echocardiography in patients undergoing orthotopic liver transplantation: A pooled analysis of accuracy, perioperative and long term cardiovascular prognosis. Int. J. Cardiovasc. Imaging 2013, 29, 1741-1748. [CrossRef]

41. Bhutani, S.; Tobis, J.; Gevorgyan, R.; Sinha, A.; Suh, W.; Honda, H.M.; Vorobiof, G.; Packard, R.R.; Steadman, R.; Wray, C.; et al. Accuracy of stress myocardial perfusion imaging to diagnose coronary artery disease in end stage liver disease patients. Am. $J$. Cardiol. 2013, 111, 1057-1061. [CrossRef]

42. Reddy, S.T.; Thai, N.L.; Oliva, J.; Tom, K.B.; Dishart, M.K.; Doyle, M.; Yamrozik, J.A.; Williams, R.B.; Shah, M.; Wani, A.; et al. Cardio-hepatic risk assessment by CMR imaging in liver transplant candidates. Clin. Transplant. 2018, 32, e13229. [CrossRef]

43. Dimitroglou, Y.; Aggeli, C.; Alexopoulou, A.; Mavrogeni, S.; Tousoulis, D. Cardiac Imaging in Liver Transplantation Candidates: Current Knowledge and Future Perspectives. J. Clin. Med. 2019, 8, 2132. [CrossRef]

44. Worthley, S.G.; Farouque, H.O.; Helft, G.; Meredith, I.T. Coronary artery imaging in the new millennium. Hear. Lung Circ. 2002, 11, 19-25. [CrossRef]

45. Cury, R.C.; Abbara, S.; Achenbach, S.; Agatston, A.; Berman, D.S.; Budoff, M.J.; Dill, K.E.; Jacobs, J.E.; Maroules, C.D.; Rubin, G.D.; et al. CAD-RADSTM Coronary Artery Disease- Reporting and Data System. An expert consensus document of the Society of Cardiovascular Computed Tomography (SCCT), the American College of Radiology (ACR) and the North American Society for Cardiovascular Imaging (NASCI). Endorsed by the American College of Cardiology. J. Cardiovasc. Comput. Tomogr. 2016, 10, 269-281. [CrossRef]

46. Joshi, P.H.; Blaha, M.J.; Budoff, M.J.; Miedema, M.D.; McClelland, R.L.; Lima, J.A.; Agatston, A.S.; Blankstein, R.; Blumenthal, R.S.; Nasir, K. The 10-Year Prognostic Value of Zero and Minimal CAC. JACC Cardiovasc. Imaging 2017, 10, 957-958. [CrossRef]

47. Blaha, M.J.; Cainzos-Achirica, M.; Greenland, P.; McEvoy, J.W.; Blankstein, R.; Budoff, M.J.; Dardari, Z.; Sibley, C.T.; Burke, G.L.; Kronmal, R.A.; et al. Role of Coronary Artery Calcium Score of Zero and Other Negative Risk Markers for Cardiovascular Disease: The Multi-Ethnic Study of Atherosclerosis (MESA). Circulation 2016, 133, 849-858. [CrossRef]

48. Hedgire, S.; Baliyan, V.; Zucker, E.J.; Bittner, D.O.; Staziaki, P.V.; Takx, R.A.P.; Scholtz, J.-E.; Meyersohn, N.; Hoffmann, U.; Ghoshhajra, B. Perivascular Epicardial Fat Stranding at Coronary CT Angiography: A Marker of Acute Plaque Rupture and Spontaneous Coronary Artery Dissection. Radiology 2018, 287, 808-815. [CrossRef] 
49. Mechelinck, M.; Hartmann, B.; Hamada, S.; Becker, M.; Andert, A.; Ulmer, T.F.; Neumann, U.P.; Wirtz, T.H.; Koch, A.; Trautwein, C.; et al. Global Longitudinal Strain at Rest as an Inde-pendent Predictor of Mortality in Liver Transplant Candidates: A Retrospective Clinical Study. J. Clin. Med. 2020, 9, 2616. [CrossRef]

50. Andert, A.; Ulmer, T.F.; Schöning, W.; Kroy, D.; Hein, M.; Alizai, P.H.; Heidenhain, C.; Neumann, U.; Schmeding, M. Grade of donor liver microvesicular steatosis does not affect the postoperative outcome after liver transplantation. Hepatobiliary Pancreat. Dis. Int. 2017, 16, 617-623. [CrossRef] 